ARTICLE

https://doi.org/10.1038/s41467-019-08374-z

\title{
A multi-substrate screening approach for the identification of a broadly applicable Diels-Alder catalyst
}

Hyejin Kim¹,2, Gabriela Gerosa1, Jonas Aronow¹, Pinar Kasaplar¹, Jie Ouyang¹, Julia B. Lingnau , Paul Guerry ${ }^{1}$, Christophe Farès ${ }^{1} \&$ Benjamin List $\mathbb{D}^{1}$

When developing a synthetic methodology, chemists generally optimize a single substrate and then explore the substrate scope of their method. This approach has led to innumerable and widely-used chemical reactions. However, it frequently provides methods that only work on model substrate-like compounds. Perhaps worse, reaction conditions that would enable the conversion of other substrates may be missed. We now show that a different approach, originally proposed by Kagan, in which a collection of structurally distinct substrates are evaluated in a single reaction vessel, can not only provide information on the substrate scope at a much earlier stage in methodology development, but even lead to a broadly applicable synthetic methodology. Using this multi-substrate screening approach, we have identified an efficient and stereoselective imidodiphosphorimidate organocatalyst for scalable Diels-Alder reactions of cyclopentadiene with different classes of $\alpha, \beta$-unsaturated aldehydes.

\footnotetext{
${ }^{1}$ Max-Planck-Institut für Kohlenforschung, Kaiser-Wilhelm-Platz 1, D-45470 Mülheim an der Ruhr, Germany. ${ }^{2}$ Therapeutics \& Biotechnology Division, Korea Research Institute of Chemical Technology, 34114 Daejeon, Republic of Korea. Correspondence and requests for materials should be addressed to B.L. (email: list@kofo.mpg.de)
} 
T he Diels-Alder reaction is one of the most powerful transformations in chemical synthesis and generates sixmembered cyclic products with up to four stereogenic centers. Among the most notable advances of this reaction has been the development of catalytic asymmetric versions. In addition to a variety of chiral Lewis acid catalysts ${ }^{1-3}$, organic molecules also catalyze Diels-Alder reactions stereoselectively ${ }^{4-6}$. Moreover, the Diels-Alder reaction between $\alpha, \beta$-unsaturated aldehydes and dienes has attracted particular attention due to not only the synthetic utility of aldehydes, but also its wide applicability in the synthesis of drugs, natural products, and fragrances ${ }^{7}$. For example, chiral secondary amines catalyze highly enantioselective Diels-Alder reactions of $\beta$-monosubstituted enals ${ }^{8-13}$. However, these catalysts typically give moderate diastereoselectivities and cannot readily be used with $\alpha$-substituted enals ${ }^{14-16}$. In addition, most reported catalysts that convert $\alpha$-substituted enals display a limited scope in terms of tolerated substituents ${ }^{1-3,14-20}$. Despite intense research in this area, a general catalyst of the Diels-Alder reaction that can accommodate a broad range of structurally distinct enals with cyclopentadiene has yet to be developed.

Realizing limitations of the model substrate approach (Fig. 1a), Kagan et al. suggested a catalyst screening that involves the utilization of a pooled collection of different substrates as an alternative method (Fig. 1b) ${ }^{21}$. The concept has originally been exemplified in the asymmetric reduction of ketones and has subsequently been applied to identify chiral ligands for metalcatalyzed asymmetric transformations such as additions of diethylzinc, hydroformylations, and hydrogenations ${ }^{22-25}$. The two main advantages of multi-substrate screenings are that information about the scope of a catalyst is revealed early on, and that catalysts that perform suboptimally with the model substrate but excellently with others, can still be identified. Challenges of multisubstrate screenings include the difficulty of developing an accurate analytical assay that can simultaneously differentiate all substrates and all stereoisomeric products. Furthermore, unproductive interactions between substrates and products as well as kinetic competition may complicate the analytics and exacerbate the readout of the assay. Nonetheless, the multi-substrate screening approach has not previously led to a general and broadly applicable catalyst and we became interested in applying it to a challenging synthetic problem. We report here the use of a multi-substrate screening approach for the development of a general catalyst of the asymmetric [4+2] cycloaddition of diverse $\alpha, \beta$-unsaturated aldehydes with cyclopentadiene.

\section{Results}

Assay development. We initiated our studies by establishing an assay to screen several structurally distinct enal dienophiles simultaneously (Fig. 2a). Six representative $\alpha, \beta$-unsaturated aldehydes were selected according to the position, nature, and size of the substituents (1a-1f), and to enable product separation on a single chiral stationary gas chromatography (GC) phase. In addition to $\alpha$ and $\beta$-monosubstituted enals $\mathbf{1 a}-\mathbf{1 d}$, substrates $\mathbf{1 e}$ and 1f were chosen as acyclic and cyclic $\alpha, \beta$-disubstituted enals. When a representative of a particular substrate class led to product peak overlaps, a minor modification quickly provided baseline separation. For example, the ethyl-substituted aldehyde 1a was employed instead of its methyl analog to circumvent product peak overlap with cycloadduct $3 \mathbf{c}$ during GC separation. Gas chromatography

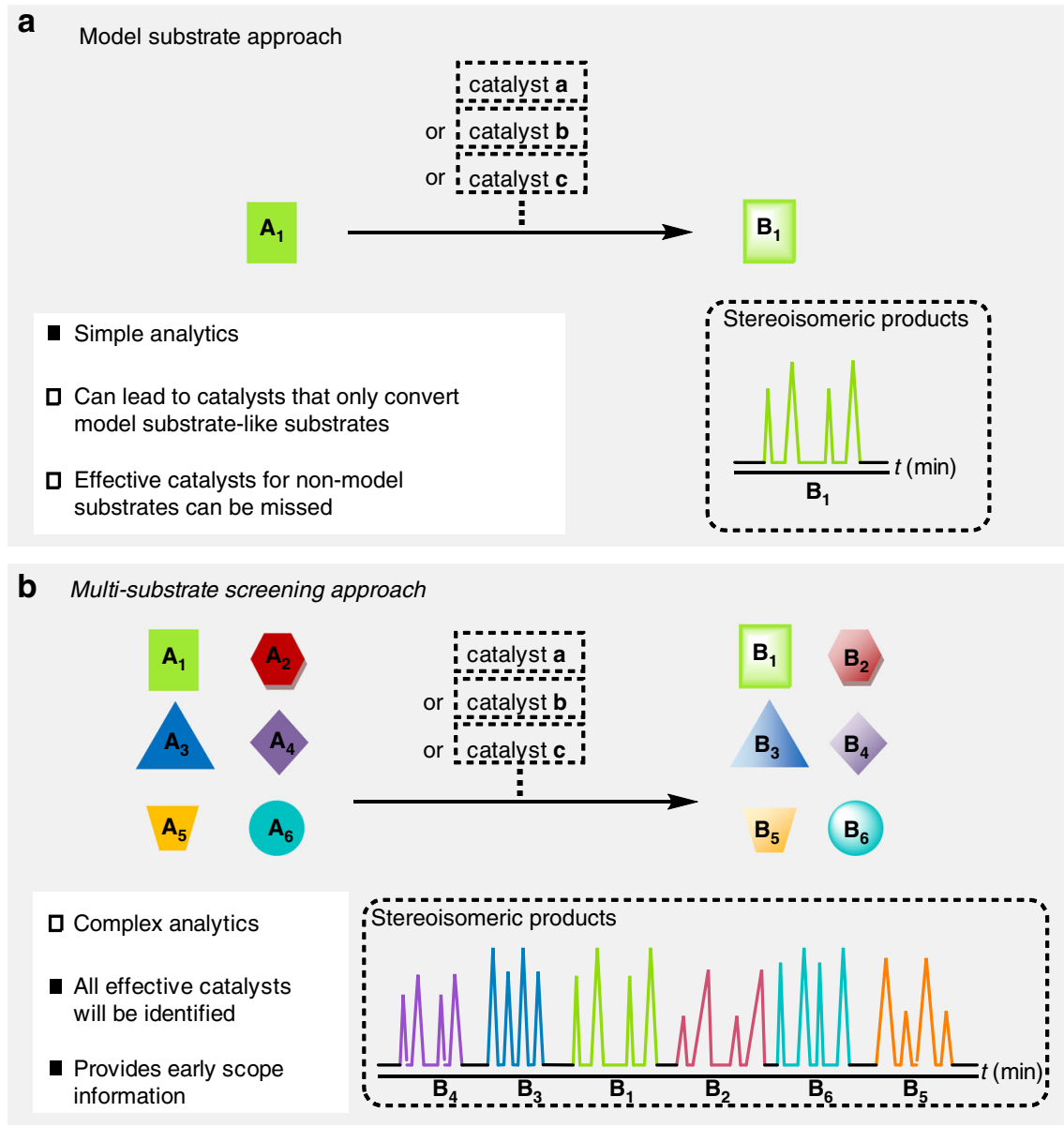

Fig. 1 Two approaches to identify a selective catalyst. a Model substrate approach vs. b multi-substrate screening approach 
a

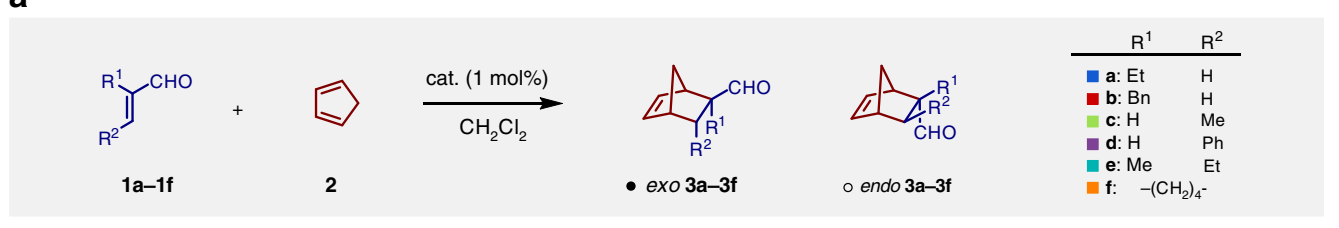

b

Mixture of exo/endo products $\mathbf{3 a}-\mathbf{3 f}$

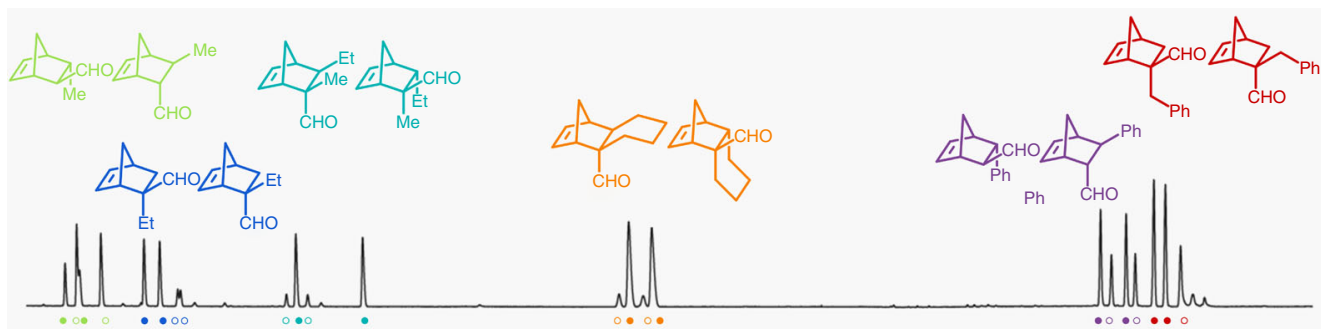

C

Product mixture with $1 \mathrm{~mol} \%$ of IDPi $4 \mathrm{~h},-100^{\circ} \mathrm{C}, 2 \mathrm{~d}$
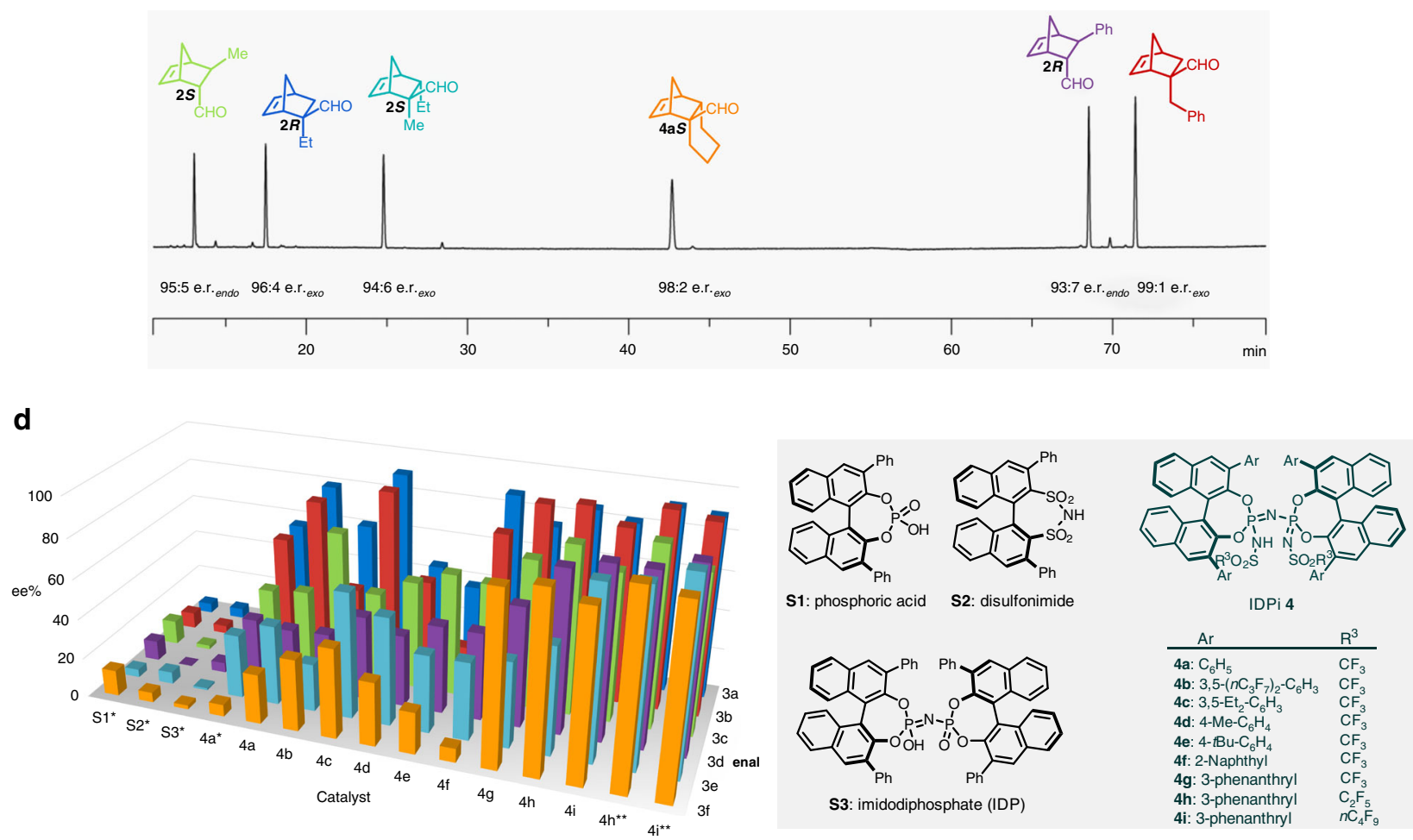

S1: phosphoric acid S2: disulfonimide

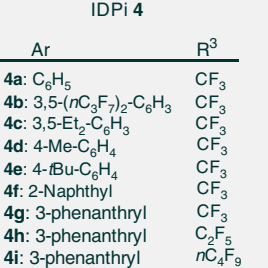

Fig. 2 Multi-substrate screening of Diels-Alder reactions of $\alpha, \beta$-unsaturated aldehydes and cyclopentadiene. a Investigated reactions. $\mathbf{b}$ GC chromatogram of the stereoisomeric product mixture. c Chromatogram of the product mixture using catalyst $\mathbf{4 h}$. $\mathbf{d}$ Graphical representation of a subset of the multi-substrate screening. ${ }^{\star}$ Reactions at room temperature. ${ }^{\star}{ }^{\star}$ Reactions at $-100^{\circ} \mathrm{C}$. For detailed reaction conditions and results, see Supplementary Note 2

with 2,3-dimethyl-6-tert-butyldimethylsilyl- $\beta$-cyclodextrin as chiral stationary phase was applied to measure the stereoisomeric ratios of all possible products in the crude mixture. A chromatogram with 23 distinct peaks (endo $\mathbf{3 b}$ could not be separated under the described condition) was established and used as the platform for the multisubstrate screening (Fig. 2b).

Catalyst screening with multiple substrates. With this robust analytical protocol established, we carried out a simultaneous catalyst screening using pooled substrates. Different Brønsted acid catalysts including phosphoric acid $\mathbf{S 1}{ }^{26,27}$, disulfonimide $\mathbf{S 2}{ }^{28,29}$, and imidodiphosphate $\mathbf{S} 3^{30}$ all provided the desired cycloaddition products, albeit sometimes with moderate reactivity and generally with poor stereoselectivities (Fig. 2d and Supplementary Table 1). A remarkable improvement of reactivity and stereoselectivity was observed using highly acidic and confined imidodiphosphorimidate (IDPi) catalyst $\mathbf{4 a}^{31-34}$, and further enhancement of enantiomeric ratios in all reactions was observed at $-78^{\circ} \mathrm{C}$. Thus, we focused on screening IDPi catalysts for the stereoselective cycloaddition of $\alpha, \beta$-unsaturated aldehydes (1a-1f) and cyclopentadiene 2 (Fig. $2 \mathrm{~d}$, for detailed results on the optimization of reaction conditions, see the Supplementary Table 2).

From screening a wide range of IDPi catalysts representatively depicted in Fig. $2 d$, we found that catalyst $4 \mathbf{c}$ showed excellent stereoselectivity exclusively with $\alpha$-substituted enals (3a: 92:8 exo/endo, 95.5:4.5 e.r. exo 3b: 91:9 exo/endo, 94.5:5.5 e.r. exo ), while aldehydes having $\beta$-substituents (1c-1f) were not converted 


\section{Table 1 Substrate scope of the Diels-Alder reaction}

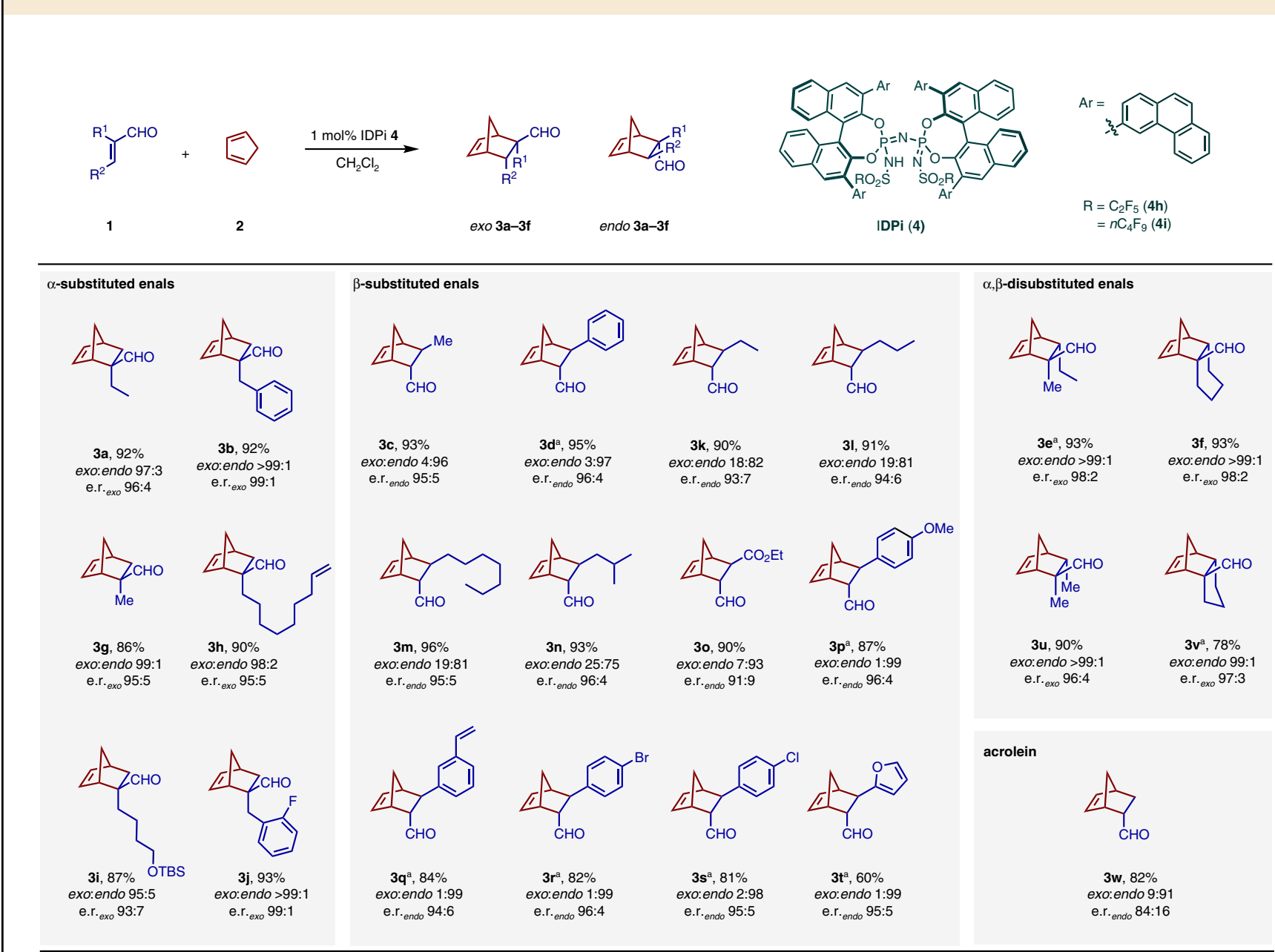

Reactions were performed with $\alpha, \beta$-unsaturated aldehydes $\mathbf{1}(0.3 \mathrm{mmol})$, cyclopentadiene $\mathbf{2}$ (5.0 equiv.) and IDPi catalyst $\mathbf{4 h}(1 \mathrm{~mol} \%)$ in $\mathrm{CH}_{2} \mathrm{Cl} 2(0.3 \mathrm{~mL})$ at $-100{ }^{\circ} \mathrm{C}$ or $-110{ }^{\circ} \mathrm{C}$ for $2-5$ days. All yields are those of isolated products. Diastereomeric ratios (exo/endo) were determined by ${ }^{1} \mathrm{H}$ nuclear magnetic resonance (NMR) analysis and enantiomeric ratios (e.r.) were determined by $\mathrm{GC}$ or high pressure liquid chromatography (HPLC) analysis. The relative and absolute configurations of cycloadducts were determined by comparison of the data with those reported. ${ }^{\mathrm{C} C a t a l y s t} \mathbf{4 i}$ was used. See the Supplementary Methods.

efficiently and stereoselectively (3c: 10:90 exo/endo, 73:27 e.r. endo; $_{3} \mathbf{3 d -}$ 3f: $<5 \%$ conv.). In contrast, catalyst $4 \mathbf{e}$ imparted higher enantioselectivities for $\beta$-monosubstituted dienophiles 1c and 1d (3c: 6:94 exo/endo, 81:19 e.r. endo ; 3 : 2:98 exo/endo, $72: 28$ e.r. endo). Notably, the most favorable results were obtained using IDPi catalysts involving polycyclic aromatic substituents at the 3,3'-positions of the 1,1'-bi-2naphthol (BINOL) backbone. For example, catalyst $\mathbf{4 g}$ gave relatively high stereoselectivities when converting enals 1a-1f. Further investigations to tune the chiral environment of the catalyst by modifying the inner substituent $\mathrm{R}^{3}$ improved the enantioselectivities of the major diastereomers $(\mathbf{4 g}-\mathbf{4 i})^{33,34}$. Finally, we were delighted to find that catalysts $\mathbf{4 h}$ and $\mathbf{4 i}$ showed excellent reactivity and stereoselectivity for all pooled $\alpha, \beta$-unsaturated aldehydes (1a-1f), achieving full consumption of all dienophiles with only $1 \mathrm{~mol} \%$ of the catalyst (Figs. 2c, d, for detailed reaction conditions and results, see the Supplementary Tables 2-5).

\section{Discussion}

Importantly, individual experiments using aldehydes 1a-1f separately corresponded well to the multi-substrate experiments, providing consistently high yields and stereoselectivities. Moreover, the optimized catalytic conditions were efficient for reacting a broad range of $\alpha, \beta$-unsaturated aldehydes (Table 1). Variations of the size of the $\alpha$-substituent were well tolerated, giving exoenriched cycloadducts with excellent enantioselectivities (3a, 3b, 3g-3j; 96:4-99:1 exo/endo, 93:7-99:1 e.r. exo $_{\text {ox }}$. In contrast, dienophiles bearing an aromatic substituent at the $\beta$-position yielded highly enantioenriched endo products (3d, 3p-3t; 3:97-1:99 exo/endo, 94:6-97:3 e.r.endo) while $\beta$-aliphatic substituents gave moderate to good diastereoselectivities (3c, 3k-3n; 25:75-4:96 exo/endo, 91:9-96:4 e.r.endo). Consistent with the observation during the multi-substrate screening, $\alpha, \beta$-disubstituted substrates furnished exo-products in good yields with high diastereo- and enantioselectivities (3e, 3f, 3u and 3v). Acrolein afforded product $3 \mathbf{w}$ in relatively good yield and stereoselectivity. The reaction was also tolerant of functional groups such as an alkene, a silyl ether, halides, and heteroarenes at the dienophiles, maintaining high yields and stereoselectivities (3h-3j, and 3o-3t). Notably, all dienophiles (1a-1w) underwent the asymmetric Diels-Alder reaction with cyclopentadiene $\mathbf{2}$ with generally good to excellent diastereoselectivity and enantioselectivity in the presence of either catalysts $4 \mathrm{~h}$ or $\mathbf{4 i}$.

Furthermore, efficiency and preparative utility of our Brønsted acid catalyzed reaction was demonstrated by large scale experiments with aldehydes $\mathbf{1 b}$ and $\mathbf{1 c}$ (Fig. 3). A decagram scale reaction using $0.1 \mathrm{~mol}$ of aldehyde $\mathbf{1 b}$ and only $0.9 \mathrm{~mol} \%$ of catalyst $\mathbf{4 h}$ was performed to afford $21 \mathrm{~g}$ of product $\mathbf{3 b}$ (98\% yield, exo/endo, > 99:1, 99:1 

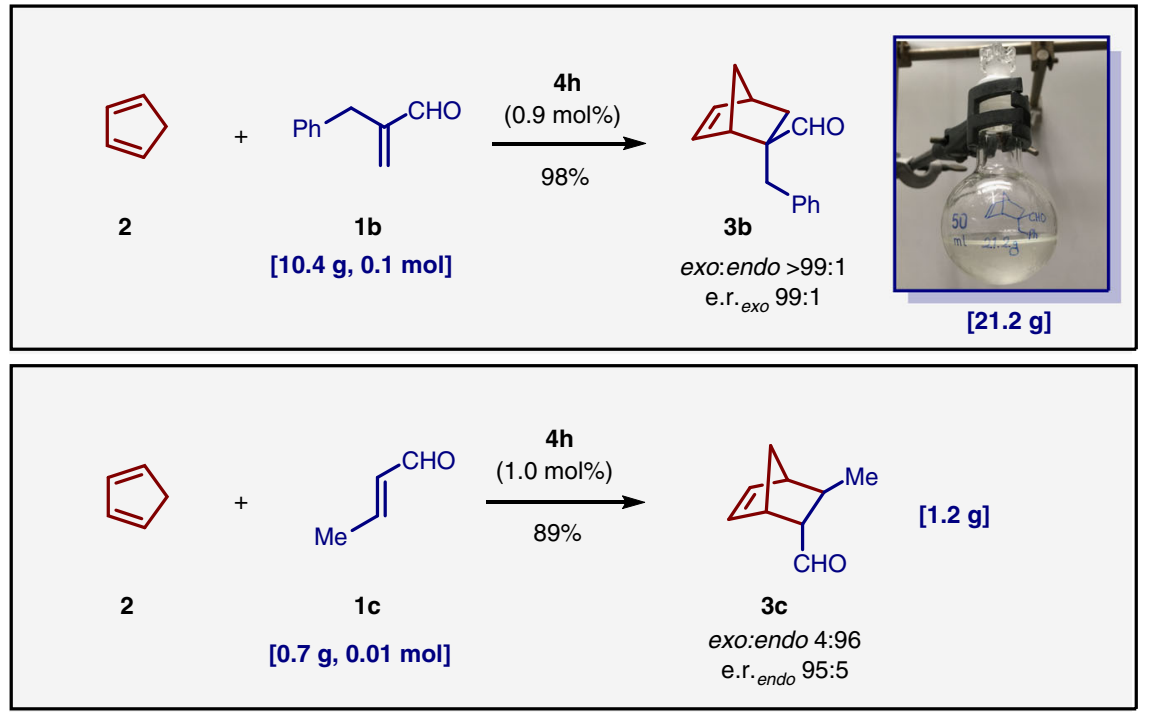

Fig. 3 Large scale experiments. Two gram scale experiments were conducted with each cyclopentadiene and aldehyde $\mathbf{1 b}$ and aldehyde $\mathbf{1 c}$, respectively. $21.2 \mathrm{~g}$ of pure product $\mathbf{3} \mathbf{b}$ was obtained
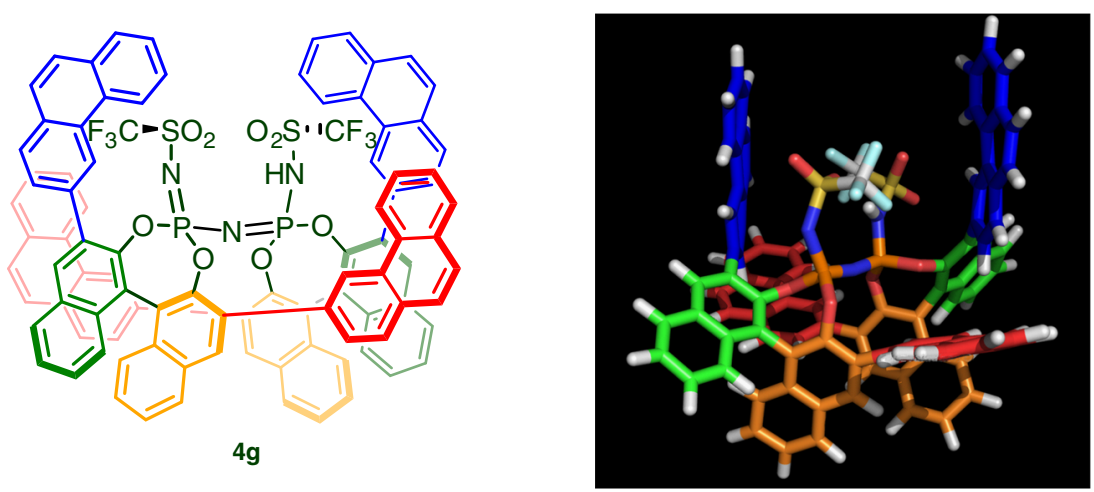

- Rigid aromatic scaffold stabilized by a network of $\pi$-stacking interactions
- No detectable rotameric exchange of 3-phenanthryl substituents
- Upper 3-phenanthryl groups form a $9 \AA$-wide, sterically confined access to
the catalytic center
- Chiral, right-handed twist of the $\mathrm{CF}_{3}$ groups about the pseudo- $C_{2}$ symmetry axis

Fig. 4 The solution structure of catalyst $\mathbf{4 g}$. Structural characteristics of our catalysts were revealed by using NMR-based models

e.r.exo). A $0.01 \mathrm{~mol}$ scale reaction of aldehyde $1 \mathrm{c}$ and cyclopentadiene 2 with $1 \mathrm{~mol} \%$ of catalyst $4 \mathrm{~h}$ furnished $1.2 \mathrm{~g}$ of product $3 \mathrm{c}$ in high yield and stereoselectivities (89\% yield, exo/endo, 4:96, 95:5 e.r. endo). $^{\text {) }}$ In both cases, catalyst $4 \mathbf{i}$ was recovered by flash column chromatography and subsequent re-acidification ( $97 \%$ and $92 \%)$.

To gain structural insight regarding the activity and stereoselectivity of the 3-phenanthryl-substituted IDPis, a 10-ns molecular dynamics simulation of $\mathbf{4} \mathbf{g}$ was performed with distance restraints based on carefully evaluated nuclear Overhauser effect (NOE) contacts. The assembly of the BINOL backbone and its substituents bears strong similarity with other IDPi crystal structures $^{28,30,31}$, and defines a rigid, narrow and chiral access to the catalytic center. The important structural features are summarized in Fig. 4 (see Supplementary Note 5, Supplementary Discussions 1, 2 and Supplementary Data 1 for details).

In conclusion, we report the discovery of a general, and scalable Brønsted acid catalyst of the asymmetric Diels-Alder reaction between structurally diverse $\alpha, \beta$-unsaturated aldehydes and cyclopentadiene (2,3-dimethylbuta-1,3-diene could also be used, as described in the Supplementary Methods). While the optimal catalysts $\mathbf{4 h}$ and $\mathbf{4 i}$, in this particularly fortuitous case, may have also been identified using single substrate approaches, other more specialized catalysts such as acid $4 \mathrm{c}$ could have easily been missed. Our findings deliver a powerful Diels-Alder catalyst and suggest that multi-substrate screenings can aid in identifying broadly useful and highly stereoselective catalysts of challenging carbon-carbon bond forming reactions.

\section{Methods}

General procedure for the asymmetric Diels-Alder reaction. To a solution of the catalyst $(1-3 \mathrm{~mol} \%)$ in anhydrous $\mathrm{CH}_{2} \mathrm{Cl}_{2}(0.3 \mathrm{~mL})$, immersed in a liquid nitrogen-ethanol slush at $-116^{\circ} \mathrm{C}$, were added aldehyde $1(0.3 \mathrm{mmol}, 1.0$ equiv) and diene 2 (5.0 equiv). The resulting mixture was stirred at the described temperature. Upon completion of the reaction, $\mathrm{NEt}_{3}(50 \mu \mathrm{L})$ was added and the reaction mixture was warmed to ambient temperature. After removal of the solvent, the crude mixture was purified by column chromatography to afford product 3 . 


\section{Data availability}

The authors declare that the data supporting the findings of this study are available within the paper and its supplementary information files.

Received: 27 September 2018 Accepted: 8 January 2019

Published online: 15 February 2019

\section{References}

1. Kagan, H. B. \& Riant, O. Catalytic asymmetric Diels-Alder reactions. Chem. Rev. 92, 1007-1019 (1992).

2. Corey, E. J. Catalytic enantioselective Diels-Alder reactions: methods, mechanistic fundamentals, pathways, and applications. Angew. Chem. Int. Ed. 41, 1650-1667 (2002).

3. Johnson, J. S. \& Evans, D. A. Chiral bis(oxazoline) copper(II) complexes: versatile catalysts for enantioselective cycloaddition, aldol, Michael, and carbonyl ene reactions. Acc. Chem. Res. 33, 325-335 (2000).

4. Erkkilä, A., Majander, I. \& Pihko, P. M. Iminium catalysis. Chem. Rev. 107, 5416-5470 (2007).

5. Shen, J. \& Tan, C.-H. Brønsted-acid and Brønsted-base catalyzed Diels-Alder reactions. Org. Biomol. Chem. 6, 3229-3236 (2008).

6. Denmark, S. E. \& Beutner, G. L. Lewis base catalysis in organic synthesis. Angew. Chem. Int. Ed. 47, 1560-1638 (2008).

7. Funel, J. A. \& Abele, S. Industrial applications of the Diels-Alder reaction. Angew. Chem. Int. Ed. 52, 3822-3863 (2013).

8. Ahrendt, K. A., Borths, C. J. \& MacMillan, D. W. C. New strategies for organic catalysis: the first highly enantioselective organocatalytic Diels-Alder reaction. J. Am. Chem. Soc. 122, 4243-4244 (2000).

9. Bonini, B. F. et al. Aziridin-2-yl methanols as organocatalysts in Diels-Alder reactions and Friedel-Crafts alkylations of $\mathrm{N}$-methyl-pyrrole and $\mathrm{N}$-methylindole. Tetrahedron.: Asymmetry 17, 3135-3143 (2006).

10. Gotoh, H. \& Hayashi, Y. Diarylprolinol silyl ether as catalyst of an exoselective, enantioselective Diels-Alder reaction. Org. Lett. 9, 2859-2862 (2007).

11. $\mathrm{He}, \mathrm{H}$. et al. Camphor sulfonyl hydrazines $(\mathrm{CaSH})$ as organocatalysts in enantioselective Diels-Alder reactions. Org. Lett. 10, 2421-2424 (2008).

12. Langlois, Y., Petit, A., Rémy, P., Scherrmann, M.-C. \& Kouklovsky, C. Camphor-derived sulfonylhydrazines: catalysts for Diels-Alder cycloadditions. Tetrahedron Lett. 49, 5576-5579 (2008).

13. Kano, T., Tanaka, Y. \& Maruoka, K. exo-Selective asymmetric Diels-Alder reaction catalyzed by diamine salts as organocatalysts. Org. Lett. 8, 2687-2689 (2006).

14. Ishihara, K. \& Nakano, K. Design of an organocatalyst for the enantioselective Diels-Alder reaction with a-acyloxyacroleins. J. Am. Chem. Soc. 127, 10504-10505 (2005).

15. Sakakura, A., Suzuki, K., Nakano, K. \& Ishihara, K. Chiral 1,1'-binaphthyl2,2'-diammonium salt catalysts for the enantioselective Diels-Alder reaction with a-acyloxyacroleins. Org. Lett. 8, 2229-2232 (2006).

16. Kano, T., Tanaka, Y., Osawa, K., Yurino, T. \& Maruoka, K. Catalytic enantioselective construction of all-carbon quaternary stereocenters by an organocatalytic Diels-Alder reaction of $\alpha$-substituted $\alpha, \beta$-unsaturated aldehydes. Chem. Commun. 0, 1956-1958 (2009).

17. Hatano, M. et al. Enantioselective Diels-Alder reactions with anomalous endo/exo selectivities using conformationally flexible chiral supramolecular catalysts. Angew. Chem. Int. Ed. 50, 12189-12192 (2011).

18. Momiyama, N., Konno, T., Furiya, Y., Iwamoto, T. \& Terada, M. Design of chiral bis-phosphoric acid catalyst derived from $(R)-3,3^{\prime}-\mathrm{Di}(2$-hydroxy-3-arylphenyl) binaphthol: catalytic enantioselective Diels-Alder reaction of $\alpha, \beta$-unsaturated aldehydes with amidodienes. J. Am. Chem. Soc. 133, 19294-19297 (2011).

19. Sakakura, A., Yamada, H. \& Ishihara, K. Enantioselective Diels-Alder reaction of $\alpha$-(acylthio)acroleins: a new entry to sulfur-containing chiral quaternary carbons. Org. Lett. 14, 2972-2975 (2012).

20. Hatano, M., Goto, Y., Izumiseki, A., Akakura, M. \& Ishihara, K. Boron tribromide-assisted chiral phosphoric acid catalyst for a highly enantioselective Diels-Alder reaction of 1,2-dihydropyridines. J. Am. Chem Soc. 137, 13472-13475 (2015).

21. Gao, X. \& Kagan, H. B. One-pot multi-substrate screening in asymmetric catalysis. Chirality 10, 120-124 (1998).

22. Brouwer, A. J., van der Linden, H. J. \& Liskamp, R. M. J. Combinatorial chemistry for ligand development in catalysis: synthesis and catalysis screening of peptidosulfonamide tweezers on the solid phase. J. Org. Chem. 65, 1750-1757 (2000).

23. Duursma, A., Minnaard, A. J. \& Feringa, B. L. One-pot multi-substrate enantioselective conjugate addition of diethylzinc to nitroalkenes. Tetrahedron 58, 5773-5778 (2002).
24. Bernsmann, H. et al. PipPhos and MorfPhos: privileged monodentate phosphoramidite ligands for rhodium-catalyzed asymmetric hydrogenation. $J$. Org. Chem. 70, 943-951 (2005).

25. Satyanarayana, T. \& Kagan, H. B. The multi-substrate screening of asymmetric catalysts. Adv. Synth. Catal. 347, 737-748 (2005).

26. Akiyama, T., Itoh, J., Yokota, K. \& Fuchibe, K. Enantioselective Mannich-type reaction catalyzed by a chiral Brønsted acid. Angew. Chem. Int. Ed. 43, 1566-1568 (2004).

27. Uraguchi, D. \& Terada, M. Chiral Brønsted acid-catalyzed direct Mannich reactions via electrophilic activation. J. Am. Chem. Soc. 126, 5356-5357 (2004).

28. García-García, P., Lay, F., García-García, P., Rabalakos, C. \& List, B. A powerful chiral counteranion motif for asymmetric catalysis. Angew. Chem. Int. Ed. 48, 4363-4366 (2009).

29. James, T., van Gemmeren, M. \& List, B. Development and applications of disulfonimides in enantioselective organocatalysis. Chem. Rev. 115, 9388-9409 (2015).

30. Corić, I. \& List, B. Asymmetric spiroacetalization catalysed by confined Brønsted acids. Nature 483, 315-319 (2012).

31. Kaib, P. S. J., Schreyer, L., Lee, S., Properzi, R. \& List, B. Extremely active organocatalysts enable a highly enantioselective addition of allyltrimethylsilane to aldehydes. Angew. Chem. Int. Ed. 55, 13200-13203 (2016).

32. Lee, S., Kaib, P. S. J. \& List, B. Asymmetric catalysis via cyclic, aliphatic oxocarbenium ions. J. Am. Chem. Soc. 139, 2156-2159 (2017).

33. Liu, L. et al. Catalytic asymmetric [4+2]-cycloaddition of dienes with aldehydes. J. Am. Chem. Soc. 139, 13656-13659 (2017).

34. Tsuji, N. et al. Activation of olefins via asymmetric Brønsted acid catalysis. Science 359, 1501-1505 (2018).

\section{Acknowledgements}

Generous support from the Max Planck Society, the Deutsche Forschungsgemeinschaft (Leibniz Award to B.L. and Cluster of Excellence RESOLV, EXC 1069), and the European Research Council (Advanced Grant "C-H Acids for Organic Synthesis, CHAOS") is gratefully acknowledged. We further thank the Alexander von Humboldt Foundation for a fellowship to H.K., the Max Planck Society-Fundación Bunge y Born for a stipend for G.G., Dr. Philip S. J. Kaib and Arno Döhring for technical support, and Dr. Monika Lindner and Dr. René Pretorius for manuscript reading. Excellent service from our GC department (especially Sylvia Ruthe, Jutta Rosentreter, and Veronika Dietl) is gratefully acknowledged.

\section{Author contributions}

H.K., G.G., J.A., P.K. and J.O. jointly conducted the experiments described in this manuscript and analyzed the data. H.K. and B.L. wrote the manuscript with contributions by all other authors. J.B.L., P.G. and C.F. conducted the NMR studies. BL designed and oversaw the project.

\section{Additional information}

Supplementary Information accompanies this paper at https://doi.org/10.1038/s41467019-08374-z.

Competing interests: A patent application on the IDPi catalysts has been filed by B.L. The remaining authors declare no competing interests.

Reprints and permission information is available online at http://npg.nature.com/ reprintsandpermissions/

Journal peer review information: Nature Communications thanks the anonymous reviewers for their contribution to the peer review of this work.

Publisher's note: Springer Nature remains neutral with regard to jurisdictional claims in published maps and institutional affiliations.

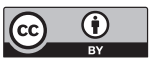

Open Access This article is licensed under a Creative Commons Attribution 4.0 International License, which permits use, sharing, adaptation, distribution and reproduction in any medium or format, as long as you give appropriate credit to the original author(s) and the source, provide a link to the Creative Commons license, and indicate if changes were made. The images or other third party material in this article are included in the article's Creative Commons license, unless indicated otherwise in a credit line to the material. If material is not included in the article's Creative Commons license and your intended use is not permitted by statutory regulation or exceeds the permitted use, you will need to obtain permission directly from the copyright holder. To view a copy of this license, visit http://creativecommons.org/ licenses/by/4.0/.

(C) The Author(s) 2019 